\title{
DISTRIBUCIÓN ESPACIAL DE SEMILLAS Y PLÁNTULAS DE DOS ESPECIES DE ÁRBOLES TROPICALES: ¿HAY CORRESPONDENCIA ENTRE LOS PATRONES? ${ }^{1}$
}

Palabras clave: Brosimum utile, Dacryodes chimantensis, Amazonia colombiana, sombra de semillas, sombra de plántulas, modelo Janzen y Connell.

Key words: Brosimum utile, Dacryodes chimantensis, colombian Amazon, seed shadow, seedling shadow, Janzen and Connell model.

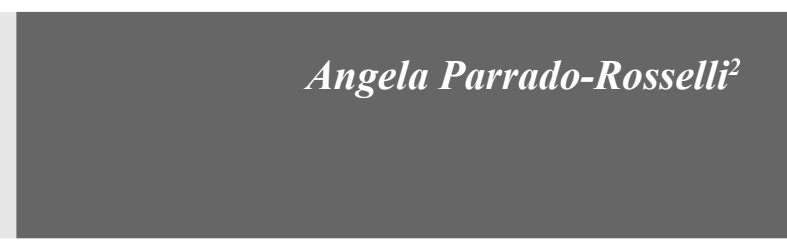

\section{RESUMEN}

Se estudiaron los patrones de distribución espacial de semillas y plántulas respecto al parental (sombra de semillas y plántulas, respectivamente) de Dacryodes chimantensis (Burseraceae) y Brosimum utile (Moraceae) dos especies de árboles tropicales característicos de los bosques de tierra firme de la Amazonia colombiana. El objetivo central consistió en evaluar si el patrón impuesto por la dispersión cambia y/o persiste en los estadios posteriores que ocurren durante la dispersión y la transición a individuos adultos. Para cada una de las especies se caracterizó la sombra de semillas y plántulas sobre el suelo a lo largo de cuatro transectos radiales de $50 \mathrm{~m}$ desde la base del árbol parental. Se determinaron las fuentes y el grado de depredación de semillas y plántulas a medida que cambia la distancia al árbol parental y se evaluó la correspondencia y/o los cambios del patrón de distribución entre estadios. Los resultados mostraron que tanto para Dacryodes como para Brosimum, la cantidad de semillas disminuyó de forma leptocúrtica con la distancia y estuvo más concentrada ha- cia el parental. Esto, sin embargo, fue mucho más pronunciado en Dacryodes que en Brosimum. La misma tendencia de distribución se presentó para la distribución de las plántulas de estas especies, la cual estuvo positivamente correlacionada con los patrones de distribución de semillas. Se encontró que la depredación de semillas y plántulas estuvo correlacionada positivamente con la densidad de semillas y negativamente con la distancia al parental. Se discuten las causas que estarían generando la alta correspondencia entre los patrones espaciales de distribución de semillas y plántulas de Dacryodes y Brosimum, sus implicaciones en la estructura de la población de estas dos especies y en el debate sobre los factores que determinan los patrones de distribución espacial de especies en los bosques tropicales.

\begin{abstract}
The spatial patterns of seed and seedling distribution relative to parent trees (seed and seedling shadow, respectively) were studied for Dacryodes chimantensis (Burseraceae) and
\end{abstract}

1 Investigación financiada por la Fundación Tropenbos Internacional Colombia; Programa de Becas de la UNESCO para el apoyo de áreas prioritarias; Organización de Los Países Bajos para la Cooperación Internacional en la Educación Superior (NUFFIC) y Fundación Het Kronendak.

2 Bióloga, Ph.D. Profesora de Biología de la Conservación y Seminario de Investigación. Proyecto curricular de Ingeniería Forestal, Facultad del Medio Ambiente y Recursos Naturales, Universidad Distrital Francisco José de Caldas. aparrador@udistrital.edu.co 
Brosimum utile (Moraceae), two common tree species of terra firme forests of Colombian Amazonia. The general objective was to assess whether the patterns imposed by seed dispersal change or persist in subsequent life stages occurring during the transition from seeds/saplings to adult stages. Seed and seedling shadows on the ground were characterized for each tree species along four $50-\mathrm{m}$ radial transects from the base of the parent tree. Causes of seed and seedling predation as a function of distance to the parent tree were determined, as well as the spatial consistency between life stages. Results showed that seed density of both Dacryodes and Brosimum declined leptokurtically with distance, and it was skewed towards the parent tree. However, seed density was more skewed and leptokurtic in Dacryodes than in Brosimum. The overall trend was maintained in the seedling stage of both species and was positively correlated with the distribution patterns of seeds. Seed and seedling predation were positively correlated with density and negatively correlated with the distance from the parent tree. Factors that could be generating the high consistency between the spatial patterns of seed and seedling distribution are discussed, as well as its implications in the population structure of both species and the debate on the factors that influence the spatial distribution of plant species in tropical rain forests.

\section{INTRODUCCIÓN}

El estudio de los patrones de distribución espacial de las especies de árboles en los bosques tropicales provee información fundamental acerca de su historia natural, dinámicas poblacionales y competencia; así como sobre los procesos que mantienen y regulan la biodiversidad. Actualmente, existe un debate creciente acerca de los factores que determinan los patrones de ocupación de espacio de las especies de plantas de los bosques tropicales. Una teoría sostiene que los requerimientos ecológicos (e.g. factores edáficos, microclimáticos) son fundamentales para entender los patrones de distribución y abundancia de las especies (Gentry 1988, Tuomisto et al. 1995) mientras que la otra sostiene que la dispersión de semillas, la competencia, la estructura de la población y la evolución de las especies son los mecanismos claves para explicar la distribución de las especies de plantas (Hubbell 1998, Wright 2002).

La dispersión de semillas comprende una serie de pasos que incluyen la producción de frutos, la remoción, el consumo y el transporte de semillas viables lejos de la copa del parental (dispersión primaria) por parte de un agente dispersor (e.g. viento, agua, animales), la remoción de semillas de ubicaciones posteriores (dispersión secundaria), la depredación de semillas y su patrón de distribución en el suelo. Este último representa el punto de partida para el establecimiento de plántulas, juveniles y adultos en el bosque (Nathan \& MullerLandau 2000, Parrado-Rosselli en prensa). La importancia de la dispersión de semillas en la regeneración, estructura y dinámica de las poblaciones de plantas, principalmente en los bosques tropicales es cada vez mayor, y día a día hay más estudios que pretenden correlacionar esta acción con los patrones de distribución espacial de los adultos en el bosque, tanto a escalas locales como intermedias (Fragoso 1997, Clark et al. 1999, Bleher \& BohningGaese 2001). Sin embargo, casi toda la evidencia es correlacional o indirecta, por lo que es necesario generar información cuantitativa que vincule las diferentes etapas de la cadena de la dispersión de semillas.

Las semillas y plántulas, son dos estadios de dicha cadena críticos para la regeneración y reclutamiento de las poblaciones. En las regiones tropicales, las altas tasas de depredación de semillas y plántulas que sufren las especies de árboles tienen grandes implicaciones en su reclutamiento (Janzen et al. 1976, De Steven 
\& Putz 1984, Howe et al. 1985, Schupp 1990). Janzen (1970) propuso que la alta diversidad de especies de plantas en los bosques tropicales es el resultado de una desproporcionada mortalidad de semillas y plántulas por ataque de herbívoros, patógenos y depredadores de semillas, la cual disminuye con el aumento de la distancia al árbol parental y/o aumenta con el incremento de la densidad de las mismas. A partir de este modelo que se le conoce como el "Modelo Janzen y Connell" (Janzen 1970, Connell 1971) es posible hacer predicciones a nivel de individuos o poblaciones de especies particulares. Janzen (1970) plantea que este fenómeno, aunque puede ocurrir para una gran cantidad de especies de plantas tropicales, no sucede en todas, así como su intensidad y escala espacial a la que opera varía (Forget 1992, Schupp 1992).

Estudios previos realizados en los bosques de tierra firme de la región del Medio Río Caquetá en la Amazonia colombiana, demuestran que las variaciones en la fertilidad de los suelos explican sólo parcialmente los patrones de distribución de especies observados (Duivenvoorden 1995, Duque et al. 2003). En estos bosques, en donde más del $70 \%$ de las especies de plantas tienen frutos adaptados para consumo por frugívoros, factores como la dispersión y depredación de semillas por animales (dónde y cuántas semillas viables son transportadas lejos del parental y cuántas quedan y en qué estado) y su posterior depredación de plántulas por herbívoros son determinantes en las dinámicas poblacionales y la distribución espacial de las especies. Entonces es importante realizar estudios que evalúen si el patrón de dispersión de semillas de las especies dispersadas por animales cambia y/o persiste en los estadios posteriores que ocurren entre la dispersión y la transición a individuos adultos (e.g. plántulas).

Por lo tanto, el objetivo de esta investigación fue examinar si existe correspondencia entre los patrones de distribución espacial (respecto al árbol parental) de semillas y plántulas de dos especies de árboles tropicales de la Amazonia colombiana. Las dos especies se caracterizan por ser abundantes (comunes) dispersadas por animales y presentar patrones de fructificación regulares, predecibles y sincrónicos. Estas características permiten controlar variables que pueden afectar los resultados obtenidos. Por ejemplo, el reclutamiento de las especies raras es, en muchos casos, producto de limitaciones y procesos desconocidos de mortalidad de semillas y plántulas (Schupp et al. 2002) y no necesariamente consecuencia de la dispersión. De la misma manera, especies con patrones claros de fructificación las hacen predecibles para los animales frugívoros, y por lo tanto permite tener información sobre las posibles causas que generarían una explotación diferencial por parte de animales.

Los objetivos específicos fueron 1) caracterizar la distribución de las semillas en el suelo y plántulas a lo largo de transectos de $50 \mathrm{~m}$ desde el árbol parental al final de la estación de fructificación de cada árbol; 2) determinar las fuentes y el grado de depredación de semillas y plántulas a medida que cambia la distancia al árbol parental y 3) evaluar la correspondencia y/o los cambios del patrón de distribución entre estadios y discutir los factores que pueden explicarlos. Es necesario aclarar que la depredación y distribución de semillas en el suelo evaluada en la presente investigación es aquella obtenida al final de la estación de fructificación de cada árbol, cuando los animales ya han moldeado, reacomodado y reorganizado la distribución de las mismas bien sea por dispersión primaria (consumo y transporte de semillas viables lejos de la copa del parental por parte de un frugívoro) dispersión secundaria (remoción de semillas de ubicaciones posteriores) y depredación (Sánchez-Cordero \& Martínez-Gallardo 1998).

Revista Colombia Forestal Vol. 10 No. 20 - Diciembre 2007 


\section{MATERIALES Y MÉTODOS}

\section{AREA DE ESTUDIO}

El trabajo de campo se llevó a cabo en un bosque de tierra firme del plano sedimentario Terciario (PST) en cercanías a la comunidad indígena Nonuya de Peña Roja, en la región del Medio Río Caquetá, departamento del Amazonas, Colombia $\left(0^{\circ} 39^{\prime} 05^{\prime \prime} \mathrm{S}, 7^{\circ} 04^{\prime} 45^{\prime}\right.$ 'O). El PST es la mayor unidad del paisaje de esta región. La precipitación promedio anual es $3060 \mathrm{~mm}$, con una moderada estación seca de diciembre a febrero, mientras que mayo y junio son los meses más lluviosos (Duivenvoorden \& Lips 1993). Las familias dominantes en el área de estudio son Fabaceae, Lecythidaceae, Arecaceae y Dipterocarpaceae (Castaño-A. 2003, Londoño-Vega \& Alvarez-Dávila 1997).

\section{ESPECIES ESTUDIADAS}

Dacryodes chimantensis Steyermark y Maguire (1967) (Burseraceae) (de aquí en adelante Dacryodes) se encuentra en los bosques húmedos tropicales en alturas menores a $1800 \mathrm{~m}$ de la Amazonia nor-occidental (Ecuador, Perú, Venezuela y Colombia). En la región del Medio Río Caquetá, el laurel de perico (nombre local) es bastante abundante en los bosques bien drenados con suelos de baja fertilidad (Duivenvoorden \& Lips 1993, Londoño-Vega \& Alvarez-Dávila 1997). Son árboles dioicos del dosel medio y alto. Sus frutos son drupas indehiscentes de una sola semilla, con fuerte olor a trementina, que maduran de verde a amarillo. Estos son elipsoides con un diámetro mayor de $26 \pm 1 \mathrm{~mm}$ (media $\pm \mathrm{SD}$ ) y un diámetro menor de $14 \pm 1 \mathrm{~mm}(\mathrm{n}=50)$. El peso seco de cada fruto es $0.6 \pm 0.3 \mathrm{~g}(\mathrm{n}=50)$. El tamaño de las semillas es en promedio $22 \pm$ $3 \mathrm{~mm} \times 13 \pm 1 \mathrm{~mm}(\mathrm{n}=50)$. Los frutos de Dacryodes se caracterizan por un mesocarpio resinoso-aceitoso el cual es bastante importante en la dieta de frugívoros especializados (e.g. Steatornis; Snow 1962). Según estudios previos, observaciones en campo y la revisión de especimenes de herbario colectados en la Amazonia colombiana (Herbario Amazónico Colombiano - COAH y Herbario Nacional Colombiano - COL) la fructificación de $\mathrm{Da}$ cryodes es extendida ( $>5$ meses) supra-anual (cada 2 o 3 años) con un pico en los meses más húmedos del año (abril - junio; Parrado-Rosselli 2005). Dacryodes es también importante en la etnobotánica de las comunidades indígenas del área. Las yemas son utilizadas para sanar picaduras de escorpiones y serpientes y la resina (incienso) es utilizada para iluminación, rituales, protección contra demonios, enfermedades y como medicina para enfermedades respiratorias (Parrado-Rosselli 2005).

Brosimum utile Kunth (1846) (de aquí en adelante Brosimum) se conoce como sande, vaco, baco o lechoso y es una importante especie maderable de la familia Moraceae. Esta especie está ampliamente distribuida en el norte de Sur América y en parte de Centro América. Se encuentra principalmente en los bosques húmedos tropicales de zonas bajas y en bosques premontanos en alturas menores a los $900 \mathrm{~m}$. La subespecie amazónica, Brosimum utile subsp. ovatifolium (Ducke) C.C. Berg (1970) se encuentra en la cuenca amazónica en Colombia, Ecuador, Perú y el Brasil occidental. Brosimum es un árbol dioico de dosel, muy abundante, que se encuentra por lo general en suelos de baja fertilidad y bien drenados de la región del medio río Caquetá (Duivenvoorden \& Lips 1993, Londoño-Vega \& Alvarez-Dávila 1997). Los árboles femeninos producen drupas esféricas, carnosas, de una sola semilla (15 \pm 1 $\mathrm{mm} \times 12 \pm 1 \mathrm{~mm} ; \mathrm{n}=50)$ suculentas, de color café, dulce y con un peso de $0.6 \pm 0.1 \mathrm{~g}$ (peso seco de un fruto, $\mathrm{n}=50$ ). Las semillas son esféricas $(0.41 \pm 0.04 \mathrm{~mm})$ y están cubiertas por un delgado pericarpio color café. Fructifica entre 1 y 2 veces al año, con una duración intermedia (1-5 meses). El primer pico se presenta 
en la época húmeda (abril-junio) y el segundo en octubre (Parrado-Rosselli 2005). Los frutos y semillas son atractivos para una gran cantidad de especies de aves, primates y mamíferos de suelo, particularmente pequeños roedores, tamarinos y tucanes (Janzen 1991, Stevenson et al. 2000, Parrado-Rosselli 2005). La madera de Brosimum es de densidad media y generalmente utilizada para construcciones livianas e interiores. El látex es utilizado de forma medicinal, para adherir plumas al cuerpo durante los rituales, y en mezcla se utiliza para recubrir canoas. Adicionalmente, a partir de la corteza los indígenas elaboran bolsas para transportar el mambe y vestidos para rituales.

\section{TOMA DE DATOS}

Los patrones de distribución espacial de semillas y plántulas respecto al parental (de aquí en adelante sombra de semillas y sombra de plántulas, respectivamente; Jordano \& Godoy 2002) se estudiaron en 5 árboles en fruto por especie, seleccionados al azar de una muestra de 16 individuos femeninos de Dacryodes y 10 de Brosimum localizados en un área de 95 ha que eran monitoreados cada mes para obtener su fenología (Parrado-Rosselli 2005). El estudio de Dacryodes se realizó entre enero y septiembre de 2000, y el de Brosimum entre febrero y octubre de 2002. En promedio, los árboles de Brosimum eran de mayor porte y con mayores cosechas que los árboles de Dacryodes (Tabla 1). Para Brosimum el tamaño inicial de la cosecha fue de 16620 frutos por árbol (rango 5600 - 39800 frutos) y para Dacryodes 1608 frutos por árbol (rango 216 - 5012 frutos). Este se obtuvo a través del conteo directo de frutos maduros e inmaduros en tres volúmenes de la copa de igual tamaño, seleccionados al azar. El promedio de los frutos encontrados en estos tres volúmenes se multiplicó por el total de volúmenes observados en la copa (Parrado-Rosselli et al. 2002, Parrado-Rosselli 2005, Parrado-Rosselli et al. 2006). Los árbo- les se observaron con binóculos (8X $30 \mathrm{~mm})$ y telescopio (20-60X $60 \mathrm{~mm}$ ). Adicionalmente, durante el periodo de estudio no se registraron frutos abortados para Dacryodes, mientras que para Brosimum el número de frutos se redujo por aborto, un $40.9 \%( \pm 8.5)$ por árbol. Se colectaron muestras botánicas de los individuos estudiados, las cuales se determinaron en el Herbario Amazónico Colombiano (COAH) en Bogotá, Colombia.

\section{SOMBRA DE SEMILLAS Y PLÁNTULAS}

Se registró el patrón de la distribución espacial de semillas y plántulas entre los 0-50 $\mathrm{m}$ de distancia desde la base de los 5 árboles seleccionados. Para la sombra de semillas, se registró la densidad de semillas en parcelas de $1 \times 1 \mathrm{~m}$ ubicadas cada $5 \mathrm{~m}$ a lo largo de cuatro transectos radiales de 1 x $50 \mathrm{~m}$, desde la base del árbol parental. Los transectos se establecieron con cinta métrica de $50 \mathrm{~m}$ y exactitud $1 \mathrm{~cm}$ y brújula Suunto.

Tabla 1. Características de los árboles de Dacryodes chimantensis y Brosimum utile en un bosque de tierra firme de la Amazonia colombiana. Promedio y desviación estándar de la altura, diámetro a la altura de pecho (DAP) y área de proyección de la copa sobre el suelo. $\mathrm{N}=5$ árboles por especie.

\begin{tabular}{|l|c|c|c|}
\hline \multicolumn{1}{|c|}{ Especie } & Altura $(\mathbf{m})$ & DAP $(\mathbf{c m})$ & $\begin{array}{c}\text { Área de } \\
\text { proyección de la } \\
\text { copa sobre el } \\
\text { suelo }\left(\mathbf{m}^{2}\right)\end{array}$ \\
\hline $\begin{array}{l}\text { D. chimantensis } \\
\text { B. utile }\end{array}$ & $17.2 \pm 1.8$ & $29.5 \pm 10.8$ & $74 \pm 30.2$ \\
$135.0 \pm 32.4$ \\
\hline
\end{tabular}

La sombra de semillas se evaluó al final de la estación de fructificación de cada árbol, cuando los animales ya han moldeado la distribución de las mismas bien sea por dispersión primaria (consumo y transporte de semillas viables lejos de la copa del parental por parte de un frugívoro) dispersión secundaria (remoción de semillas 
de ubicaciones posteriores) depredación y subsiguiente reorganización de las mismas (SánchezCordero \& Martínez-Gallardo 1998). Se contó el número de semillas encontradas en cada parcela, las cuales se clasificaron como viables o depredadas. Para estas últimas, se determinó la causa de depredación (i.e. vertebrados, invertebrados -larvas y/o escarabajos- y hongos) al examinar si las semillas depredadas presentaban marcas de dientes o de pico, si estaban trituradas en pedazos, o si exhibían larvas o pupas de insectos y/o orificio de salida. Debido a que la sombra de semillas evaluada es la resultante una vez ha finalizado la estación de fructificación de la especie, este procedimiento tiende a subestimar la depredación por vertebrados pues no considera semillas que cayeron antes de los registros y que fueron depredadas (desaparecidas) por vertebrados y de las cuales no queda ningún rastro. Sin embargo, se consideró importante presentar los datos de depredación por vertebrados puesto que pueden dar indicios acerca del potencial papel de estos en la regeneración de las especies.

Se determinó el patrón de distribución de plántulas a todo lo largo de los mismos 4 transectos radiales de 1 x $50 \mathrm{~m}$ descritos anteriormente. Los registros se realizaron tres meses después del final de la estación de fructificación de cada especie, la cual se consideró como el pico del proceso de establecimiento de las plántulas. Se identificaron y marcaron con una banderola y cinta fluorescente, todas las plántulas encontradas en dichos transectos. Las plántulas se clasificaron como plántulas 1 (aquellas menores de un año, recientemente establecidas o de estación de fructificación inmediatamente anterior) y plántulas 2 (aquellas mayores a un año; modificado de Hladik \& Mitja 1996). Para Dacryodes las plántulas 1 ( $<1$ año) presentaron una altura menor a $25 \mathrm{~cm}$ (rango 13 $-24 \mathrm{~cm} ; \mathrm{n}=22$ ) y las plántulas 2 ( $>1$ año) midieron entre 25 y $50 \mathrm{~cm}$ (rango $25-50 \mathrm{~cm}$; $=14$ ). Por otro lado, la altura de las plántulas 1 de Brosimum fue menor a $35 \mathrm{~cm}$ de altura (ran- go $20-32 \mathrm{~cm} ; \mathrm{n}=15)$ y la de las plántulas 2 fue menor a $70 \mathrm{~cm}$ (rango $41-68 \mathrm{~cm} ; \mathrm{n}=9$ ).

Puesto que sólo se realizó un censo en el tiempo, no fue posible evaluar la real mortalidad y depredación de las plántulas. Por lo tanto, el daño de las plántulas, se consideró como indicador potencial de mortalidad. Se consideraron como causas de depredación potencial los herbívoros (vertebrados y/o invertebrados) y patógenos o enfermedad (hojas secas, muertas, quemadas $\mathrm{y} / \mathrm{o}$ decoloradas por hongos u otra causa no determinada). Si una o más hojas de las mostraban dicho daño se consideraba como atacada por depredadores.

\section{ANALISIS DE DATOS}

Aunque algunas semillas y plántulas pueden provenir de diferentes árboles parentales, se consideró que los transectos de semillas y plántulas de todos los árboles estudiados contenían semillas o plántulas exclusivamente de dichos árboles parentales. No obstante, se tuvo en cuenta que los vecinos en un radio de $100 \mathrm{~m}$ no estuvieran ofreciendo frutos durante el periodo de estudio. Para cada parental se sumaron los datos sobre semillas y plántulas obtenidos en cada distancia de cada transecto con el fin de evadir una posible pseudoreplicación al tratar muestras como unidades de muestreo independientes (particularmente aquellas más cercanas al parental). Se calculó la moda y la curtosis de la sombra de semillas y de las plántulas. La curtosis se utilizó para medir el grado de aplanamiento o curvatura de la distribución de semillas y plántulas (Sokal $\&$ Rohlf 1980). El cociente entre la curtosis y su error estándar se utilizó como prueba de normalidad (la distribución no es normal si el cociente es menor que -2 o mayor que +2 ). Un alto valor positivo indica que la distribución presenta una mayor curvatura y mayor cola que la distribución normal, mientras que los valores negativos indican que tiende a ser más plana. Por otro lado, la moda se utilizó para describir si la distribución 
de semillas y plántulas tiende a concentrarse en la cercanía o lejanía del parental. El cociente entre la moda y su error estándar se utilizó como prueba de normalidad (la distribución no es normal si el cociente es menor -2 o mayor que +2 ). Un alto valor positivo indica que la mayoría de semillas y plántulas tienden a concentrarse más cerca del parental que en la distribución normal, mientras que los valores negativos indican que semillas y plántulas tienden a concentrarse más lejos del parental en relación a la distribución normal (Sokal \& Rohlf 1980).

La probabilidad de transición de las semillas a plántulas 1 , y de plántulas 1 a plántulas 2 se calculó como el cociente entre plántulas 1 establecidas por número de semillas registradas en cada distancia, y el cociente entre plántulas 2 por cada plántula 1 establecida. Se utilizó el coeficiente de correlación por rangos de Spearman para evaluar si la depredación de semillas y plántulas está asociada con la distancia al parental o con la densidad. Este coeficiente también se utilizó para evaluar la consistencia espacial entre estadios. Todas las pruebas se realizaron con base en Zar (1984) y Statistica (V.5.5 StatSoft 1999).

\section{RESULTADOS}

\section{SOMBRA DE SEMILLAS Y DEPREDACIÓN}

Se encontró que la distribución natural de semillas en el suelo entre los 0-50 m desde la base de los árboles parentales es más leptocúrtica y concentrada hacia el parental en Dacryodes que en Brosimum (Tabla 2; Figuras 1 y 2). La distancia media de dispersión de las semillas de Dacryodes fue de $7.1 \mathrm{~m}$, mientras que para Brosimum fue de $12 \mathrm{~m}$.

El porcentaje total de semillas depredadas entre los 0-50 m desde el parental para Dacryodes fue $45.1 \pm 17.8 \%$. Las principales causas de depredación de semillas de Dacryodes fueron hongos y larvas, mientras que los vertebrados (principalmente loros) fueron de menor importancia (Figura 3). El porcentaje total de semillas de Brosimum depredadas $(26.4 \pm 12.8 \%)$ fue menor que para Dacryodes. Las larvas de escarabajos fueron la principal causa de mortalidad de las semillas de Brosimum (Figura 3). No se observó daño de semillas de Brosimum por hongos.

La depredación de semillas de Brosimum estuvo fuertemente agregada en la cercanía al árbol parental (Tabla 2) mientras que la depredación de semillas de Dacryodes, aunque es mayor a menor distancia del parental, estuvo mejor distribuida a lo largo de los $50 \mathrm{~m}$. Para las dos especies la depredación total, así como la depredación por invertebrados estuvo positivamente correlacionada con la densidad de semillas y negativamente correlacionada con la distancia al parental (Tabla 3). La depredación de semillas de Brosimum por vertebrados no mostró correlación alguna con la densidad

Tabla 2. Resumen de la forma y distribución de la sombra de semillas de Dacryodes chimantensis y Brosimum utile en un bosque de tierra firme de la Amazonia colombiana. IC: intervalo de confianza; EE: error estándar.

\begin{tabular}{|l|c|c|c|c|c|c|c|c|}
\hline \multicolumn{1}{|c|}{ Especie } & Media $(\mathbf{m})$ & IC $(\mathbf{m})$ & Moda & EE & Moda/EE & Curtosis & EE & Curtosis/EE \\
\hline Semillas viables & & & & & & & & \\
$\quad \begin{array}{l}\text { D. chimantensis } \\
\text { B. utile }\end{array}$ & 7.1 & $6.2-8.0$ & 4.23 & 0.19 & 22.27 & 21.07 & 0.38 & 55.75 \\
Semillas depredadas & 12.0 & $11.0-12.9$ & 1.91 & 0.10 & 18.67 & 2.85 & 0.20 & 13.97 \\
$\quad$ & & & & & & & \\
D. chimantensis & 5.8 & $5.5-6.0$ & 1.97 & 0.20 & 9.99 & 1.89 & 0.39 & 4.83 \\
B. utile & 8.9 & $7.8-10.0$ & 3.03 & 0.16 & 18.53 & 9.53 & 0.33 & 29.31 \\
\hline
\end{tabular}


Tabla 3. Correlación entre la distancia al árbol parental y la densidad con la depredación de semillas de Dacryodes chimantensis y Brosimum utile en un bosque de tierra firme de la Amazonia colombiana. $\mathrm{r}_{\mathrm{s}}$ : Coeficiente de correlación por rangos de Spearman. En Negrita: $\mathrm{P}<0.005 ; \mathrm{N}=50$.

\begin{tabular}{|c|c|c|c|c|}
\hline & \multicolumn{2}{|c|}{ Dacryodes chimantensis } & \multicolumn{2}{|c|}{ Brosimum utile } \\
\hline & $r_{s}$ & $\mathbf{P}$ & $r_{s}$ & $\mathbf{P}$ \\
\hline \multicolumn{5}{|c|}{ Total semillas depredadas } \\
\hline vs. distancia & -0.680 & $<0.001$ & -0.384 & 0.028 \\
\hline vs. densidad & 0.833 & $<0.001$ & 0.677 & $<<0.001$ \\
\hline \multicolumn{5}{|c|}{ Semillas depredadas por invertebrados } \\
\hline vs. distancia & -0.644 & $<<0.001$ & -0.590 & $<<0.001$ \\
\hline vs. densidad & 0.800 & $<0.001$ & 0.785 & $<<0.001$ \\
\hline \multicolumn{5}{|c|}{ Semillas depredadas por hongos } \\
\hline vs. distancia & -0.656 & $<<0.001$ & - & - \\
\hline vs. densidad & 0.701 & $<<0.001$ & - & - \\
\hline \multicolumn{5}{|c|}{ Semillas depredadas por vertebrados } \\
\hline vs. distancia & -0.483 & $<<0.001$ & -0.074 & 0.680 \\
\hline vs. densidad & 0.537 & $<0.001$ & -0.263 & 0.139 \\
\hline
\end{tabular}

ni con la distancia al parental. Sólo se observó depredación de semillas por hongos en Dacryodes, la cual fue tanto denso como distanciodependiente.

\section{SOMBRA DE PLÁNTULAS Y DEPREDACIÓN POTENCIAL}

Se encontró que la sombra de plántulas $1(<$ 1 año) de Dacryodes fue más leptocúrtica y estuvo más concentrada en la cercanía del parental que la sombra de plántulas de Brosimum (Tabla 4; Figuras 1 y 2). En contraste con esta distribución, la sombra de plántulas 2 ( $>1$ año) de Dacryodes fue más plana y menos concentrada hacia el parental. Para Brosimum se encontró que la distribución de plántulas 2 no es leptocúrtica (Tabla 4; Figuras 1 y 2).

Respecto al daño o depredación potencial de plántulas 1 de Dacryodes entre los 0-50 m, los resultados muestran que ésta fue del 30.1 $\pm 12.9 \%$, mientras que el daño a las plántulas 1 de Brosimum fue del $19.4 \pm 10.8 \%$. Para las plántulas 2, el daño total para Dacryodes fue $43.9 \pm 10.8 \%$ y para Brosimum del 31.9 $\pm 13.2 \%$. Las causas de depredación potencial para las dos categorías de plántulas de las dos especies fueron patógenos, hongos y herbívoros (Figura 4). Para plántulas 1, los herbívoros fueron la mayor causa de daño en Dacryodes, mientras que en Brosimum lo fueron patógenos y hongos (Figura 4a). Para las dos especies, los herbívoros fueron los principales depredadores potenciales de las plántulas 2. (Figura 4b). Para las dos especies estudiadas, el daño de en general fue poco o no leptocúrtico (Tabla 4).

La depredación potencial total de plántulas de Dacryodes y aquella generada por los diferentes agentes depredadores estuvo positivamente correlacionada con la densidad y negativamente correlacionada con la distancia al árbol parental (Tabla 5). De igual forma, la depredación potencial de plántulas 1 de Brosimum (y sus causas) estuvo correlacionada con la densidad y la distancia. La depredación potencial total y por enfermedad de plántulas 2 sólo presentó una correlación negativa con la distancia al parental (Tabla 5). 


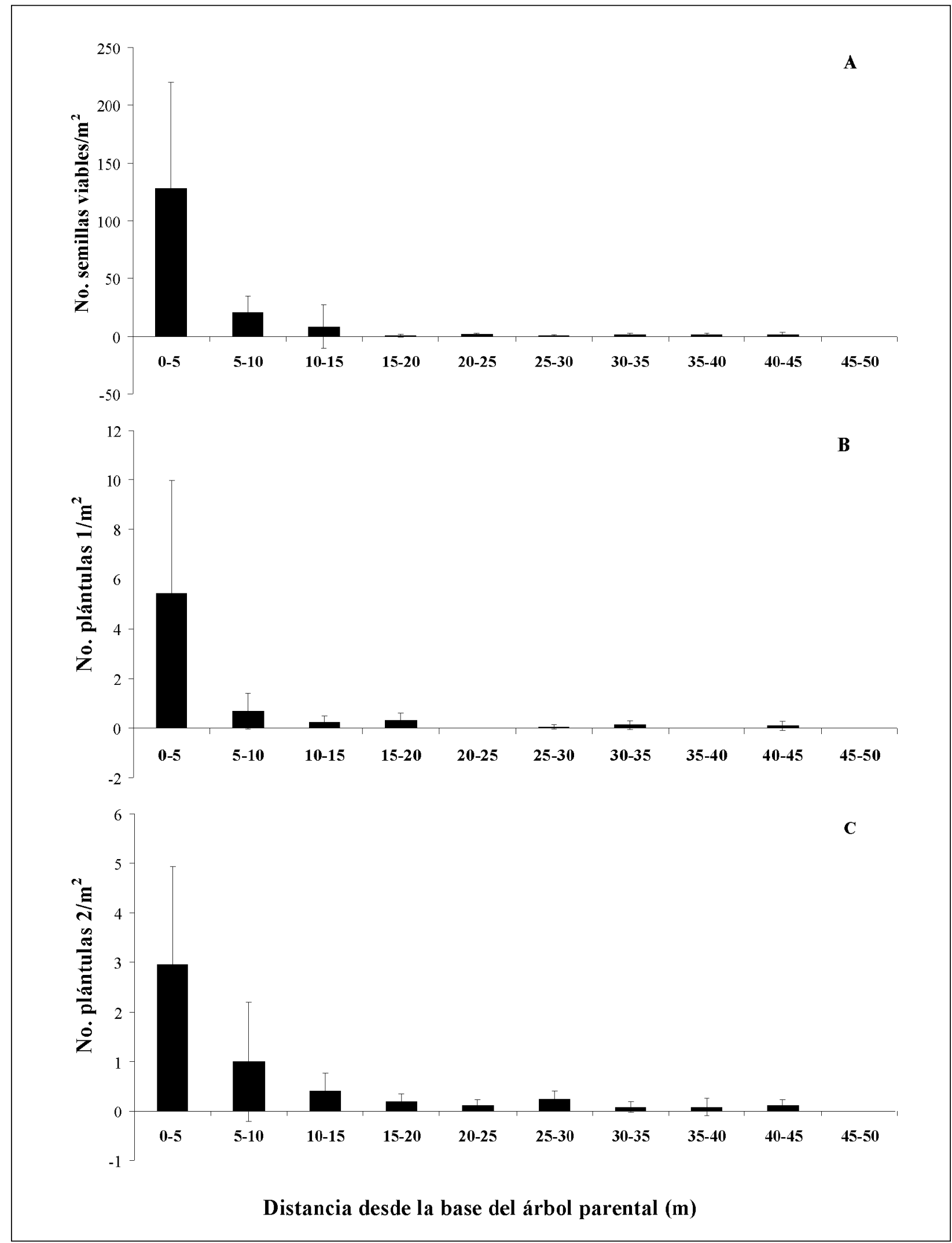

Figura 1. Promedio de la sombra de semillas (A), plántulas $1(<1$ año) (B) y plántulas 2 ( $>1$ año) (C) por árbol de Dacryodes chimantensis en un bosque de tierra firme de la Amazonia colombiana. $\mathrm{N}=5$ árboles por especie. 


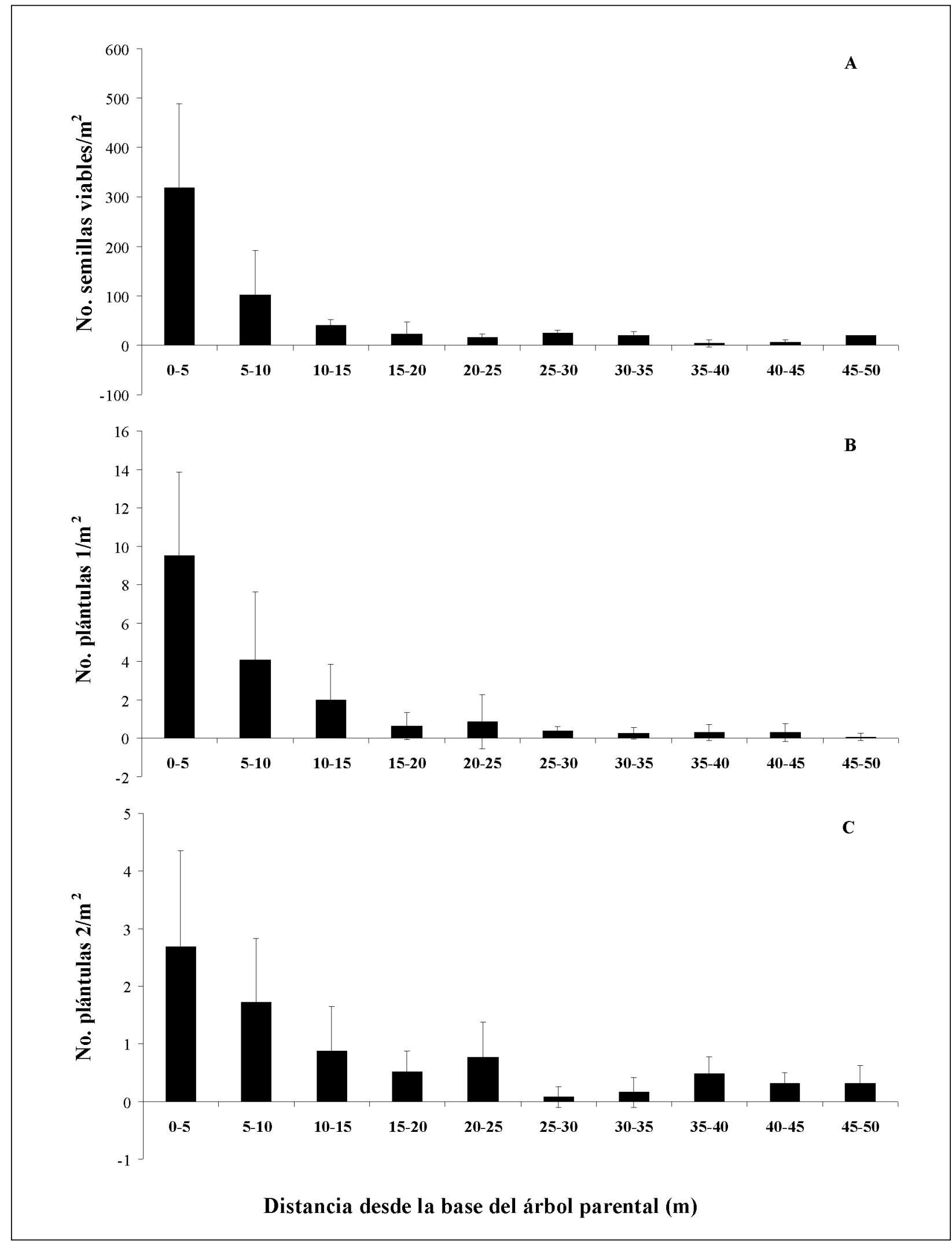

Figura 2. Promedio de la sombra de semillas (A), plántulas $1(<1$ año) (B) y plántulas 2 ( $>1$ año) (C) por árbol de Brosimum utile en un bosque de tierra firme de la Amazonia colombiana. $\mathrm{N}=5$ árboles por especie. 


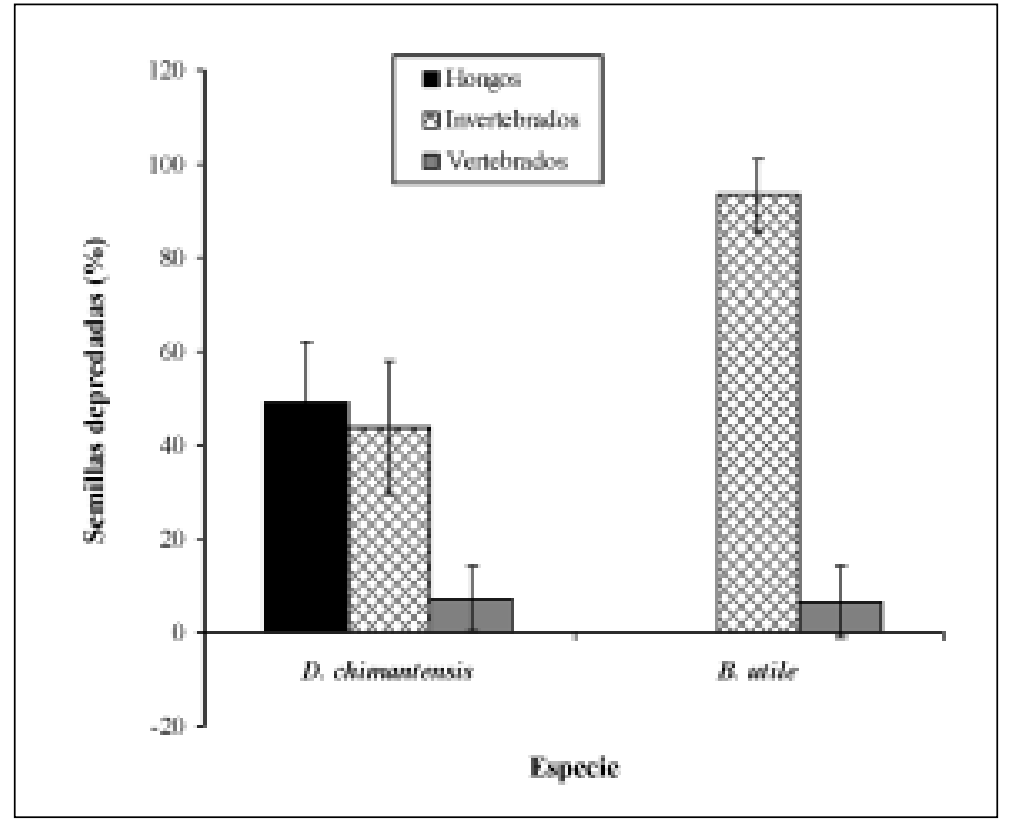

Figura 3. Fuentes de depredación de semillas de Dacryodes chimantensis y Brosimum utile en un bosque de tierra firme de la Amazonia colombiana.

Tabla 4. Resumen de la forma y distribución de la sombra de plántulas 1 ( $<1$ año) y plántulas 2 ( $>1$ año) de Dacryodes chimantensis y Brosimum utile en un bosque de tierra firme de la Amazonia colombiana. IC: intervalo de confianza; EE: error estándar. En negrita: distribución normal.

\begin{tabular}{|c|c|c|c|c|c|c|c|c|}
\hline Especie & Media (m) & IC (m) & Moda & $\mathrm{EE}$ & Moda/EE & Curtosis & $\mathrm{EE}$ & Curtosis/EE \\
\hline \multicolumn{9}{|l|}{ Plántulas 1 viables } \\
\hline D. chimantensis & 7.5 & 5.3-9.7 & 3.18 & 0.40 & 7.88 & 11.07 & 0.79 & 14.05 \\
\hline B. utile & 11.0 & $9.1-13.0$ & 2.06 & 0.25 & 8.19 & 3.93 & 0.50 & 7.90 \\
\hline \multicolumn{9}{|l|}{ Plántulas 1 dañadas } \\
\hline D. chimantensis & 7.2 & 3.3-11.1 & 2.51 & 0.72 & 3.49 & 6.34 & 1.40 & 4.53 \\
\hline B. utile & 9.7 & $6.4-12.9$ & 1.40 & 0.58 & 2.42 & 2.10 & 1.12 & 1.87 \\
\hline \multicolumn{9}{|l|}{ Plántulas 2 viables } \\
\hline D. chimantensis & 10.6 & $6.6-14.5$ & 2.33 & 0.46 & 5.12 & 5.76 & 0.89 & 6.50 \\
\hline B. utile & 17.0 & $12.5-21.5$ & 1.18 & 0.37 & 3.16 & 0.23 & 0.73 & 0.31 \\
\hline \multicolumn{9}{|l|}{ Plántulas 2 dañadas } \\
\hline D. chimantensis & 8.6 & $5.2-12.0$ & 1.37 & 0.66 & 2.08 & 1.32 & 1.28 & 1.03 \\
\hline B. utile & 12.3 & $4.9-19.7$ & 1.95 & 0.66 & 2.95 & 3.63 & 1.28 & 2.84 \\
\hline
\end{tabular}


Tabla 5. Correlación entre la distancia al árbol parental y la densidad con el daño o depredación potencial de plántulas 1 ( $<1$ año) y plántulas 2 ( $>1$ año) de Dacryodes chimantensis y Brosimum utile en un bosque de tierra firme de la Amazonia colombiana. En Negrita: $\mathrm{P}<0.005 ; \mathrm{N}=50$.

\begin{tabular}{|c|c|c|c|c|c|c|c|c|}
\hline & \multicolumn{4}{|c|}{ Dacryodes chimantensis } & \multicolumn{4}{|c|}{ Brosimum utile } \\
\hline & \multicolumn{2}{|c|}{1} & \multicolumn{2}{|c|}{2} & \multicolumn{2}{|c|}{1} & \multicolumn{2}{|c|}{2} \\
\hline & $\mathbf{r}$ & $\mathbf{P}$ & $\mathbf{r}$ & $\mathbf{P}$ & $r$ & $\mathbf{P}$ & $r$ & $\mathbf{P}$ \\
\hline Daño Total & & & & & & & & \\
\hline vs. distancia & -0.501 & $<0.001$ & -0.449 & 0.001 & -0.716 & $<<0.001$ & -0.225 & 0.117 \\
\hline vs. densidad & 0.665 & $<0.001$ & 0.625 & $<0.001$ & 0.654 & $<<0.001$ & 0.299 & 0.035 \\
\hline Daño por herbívor & & & & & & & & \\
\hline vs. distancia & -0.477 & $<0.001$ & -0.441 & 0.001 & -0.596 & $<0.001$ & -0.276 & 0.052 \\
\hline vs. densidad & 0.628 & $<0.001$ & 0.620 & $<0.001$ & 0.507 & $<0.001$ & 0.272 & 0.056 \\
\hline Daño por patógen & & & & & & & & \\
\hline vs. distancia & -0.381 & 0.006 & -0.487 & $<<0.001$ & -0.632 & $<<0.001$ & -0.263 & 0.065 \\
\hline vs. densidad & 0.393 & 0.002 & 0.572 & $<0.001$ & 0.716 & $<<0.001$ & 0.455 & $<<0.001$ \\
\hline
\end{tabular}

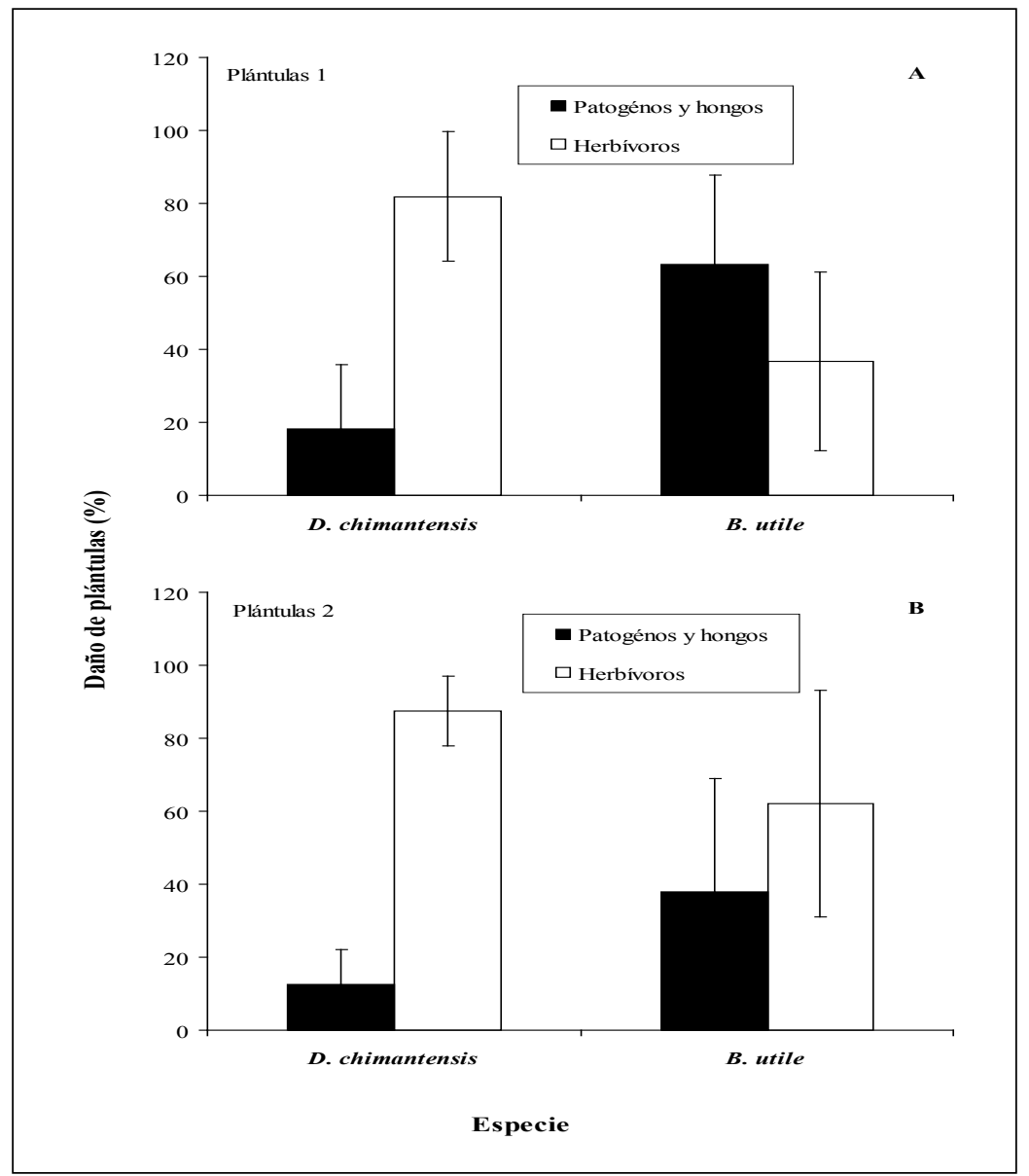

Figura 4. Fuentes de daño o depredación potencial de plántulas $1(<1$ año) (A) y plántulas 2 (> 1 año) (B) de Dacryodes chimantensis y Brosimum utile en un bosque de tierra firme de la Amazonia colombiana. 


\section{CORRESPONDENCIA ENTRE SEMILLAS Y PLANTULAS}

Se encontró una alta correspondencia entre los patrones espaciales de distribución de semillas y plántulas de Dacryodes y Brosimum (Tabla 6). Sin embargo, se encontró que en Dacryodes, la probabilidad de transición de semillas a plántulas 1 en cada distancia fue menor a 0.1 (Figura 5). La mayor probabilidad de transición de semillas a plántulas se registró entre los 0-5 $\mathrm{m}$ de distancia del parental y en segundo lugar en las distancias 5-10 m y 30-35 m (Figura 5).
Las mayores probabilidades de transición de plántulas 1 ( $<1$ año) de Dacryodes a plántulas 2 ( $>1$ año) se presentaron entre los 0-20 $\mathrm{m}$ de distancia del árbol parental, siendo la mayor a los 5-10 m (Figura 5). Por otra parte, en Brosimum, la mayor probabilidad de transición de semillas a plántulas $1(0.12)$ se presentó a los 20-25 m del parental y en segundo lugar entre los 10-15 m (Figura 6). La mayor probabilidad de transición de plántulas $1(<1$ año) a plántulas 2 ( $>1$ año) se registró en los $15-20 \mathrm{~m}$ del parental (Figura 6).

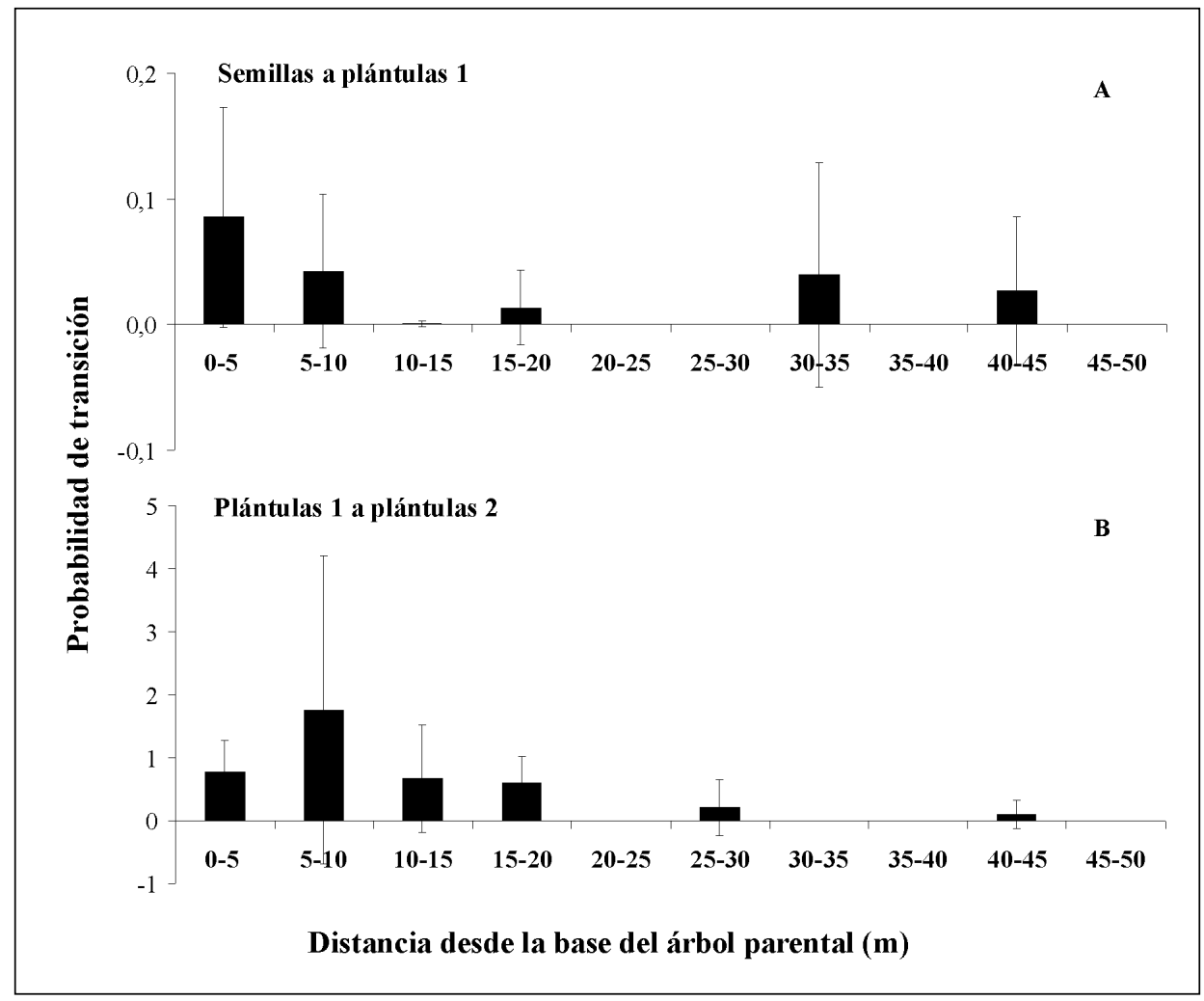

Figura 5. Probabilidad de transición de semillas a plántulas 1 (A) y de plántulas 1 a plántulas 2 (B) de Dacryodes chimantensis en un bosque de tierra firme de la Amazonia colombiana. $\mathrm{N}=5$ árboles por especie. 


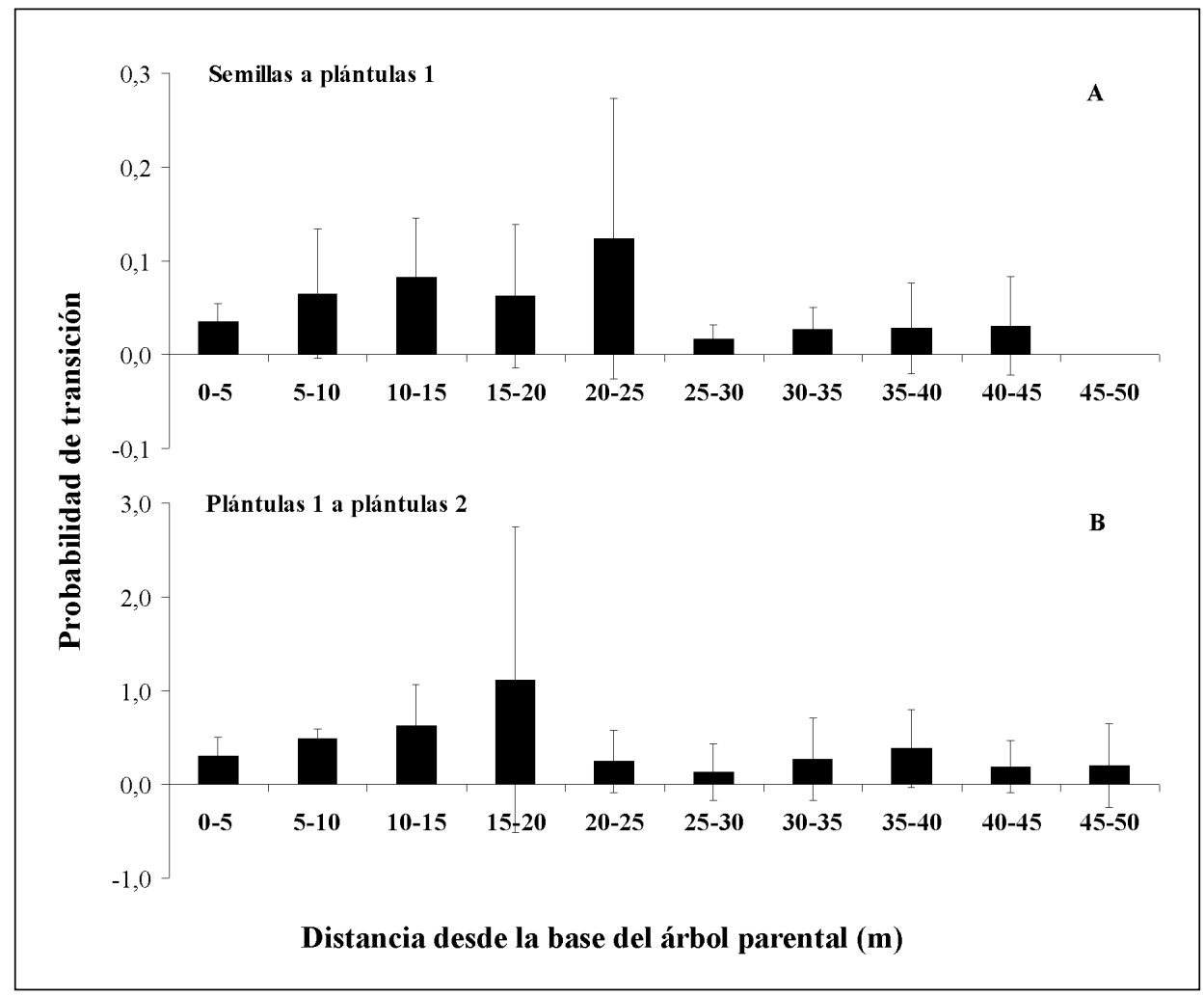

Figura 6. Probabilidad de transición de semillas a plántulas 1 (A) y de plántulas 1 a plántulas 2 (B) de Brosimum utile en un bosque de tierra firme de la Amazonia colombiana. $\mathrm{N}=5$ árboles por especie.

Tabla 6. Matriz de correlación entre la distribución espacial de los diferentes estadios de vida (i.e. semillas, plántulas 1 y plántulas 2) de Dacryodes chimantensis y Brosimum utile en un bosque de tierra firme de la Amazonia colombiana. No se incluyeron en los cálculos las plántulas 1 y plántulas 2 dañadas. $\mathrm{r}_{\mathrm{s}}$ : Coeficiente de correlación por rangos de Spearman. En negrita: $\mathrm{P}$ $<0.05, \mathrm{~N}=10$.

\begin{tabular}{|c|c|c|c|}
\hline \multicolumn{2}{|c|}{ Estadio de vida } & Plántulas 1 & Plántulas 2 \\
\hline \multicolumn{4}{|c|}{ D. chimantensis } \\
\hline \multirow[t]{2}{*}{ Semillas } & $r_{s}$ & 0.747 & 0.671 \\
\hline & $\mathrm{P}$ & 0.013 & 0.034 \\
\hline \multirow[t]{2}{*}{1} & $r_{s}$ & & 0.675 \\
\hline & $P$ & & 0.032 \\
\hline \multicolumn{4}{|l|}{ B. utile } \\
\hline \multirow[t]{2}{*}{ Semillas } & $r_{s}$ & 0.717 & 0.564 \\
\hline & $P$ & 0.020 & 0.090 \\
\hline \multirow[t]{2}{*}{1} & $r_{s}$ & & 0.802 \\
\hline & $P$ & & 0.005 \\
\hline
\end{tabular}

\section{DISCUSIÓN}

Los resultados del presente estudio sugieren que a una escala local, los patrones de distribución espacial de las semillas de Dacryodes y Brosimum se mantienen similares en la etapa de plántulas, puesto que se encontró consistencia entre la sombra de semillas de las dos especies y la distribución espacial de estadios subsecuentes. Tanto para Dacryodes como para Brosimum, la cantidad de semillas disminuyó de forma leptocúrtica con la distancia y estuvo más concentrada hacia el parental. Esto, sin embargo, fue mucho más pronunciado en Dacryodes que en Brosimum. La misma tendencia de distribución se presentó para las plántulas. Sin embargo, esta tiende a ser más plana y menos concentrada respecto al parental. Tal parece entonces que factores abióticos como microclima, radiación solar y formación 
de claros estarían afectado de forma similar el crecimiento y supervivencia de las dos especies y afectando directamente la densidad más que la distribución (Hamill \& Wright 1986, Clark et al. 1999, Bleher \& Böhning-Gaese 2001).

\section{EL PAPEL DE LA DEPREDACIÓN DE SEMILLAS Y PLANTULAS}

Factores bióticos como la depredación también estarían afectando el papel de la dispersión de semillas en moldear la futura distribución de la población. En este estudio, las dinámicas de depredación de semillas y plántulas (depredación potencial) de las dos especies fueron altamente denso y distancio-dependientes, conforme al modelo propuesto por Janzen y Connell (Janzen 1970, Connell 1971). Sin embargo, este resultó mucho más marcado en Brosimum. Tal parece, que para su exitoso reclutamiento, las semillas tendrían que ser transportadas a mayores distancias del árbol parental, aspecto que se refleja en una curva de distribución de semillas y plántulas menos pronunciada respecto a Dacryodes y en una mayor probabilidad de transición de semillas a plántulas entre los 20$25 \mathrm{~m}$ de distancia del parental. En contraste, un menor efecto Janzen y Connell en Dacryodes estaría probablemente compensando el hecho de que sus semillas y plántulas estén más concentradas en la cercanía del parental, producto de un menor consumo de frutos y una baja dispersión de semillas por parte de frugívoros (Rozo-Mora \& Parrado-Rosselli 2004, Parrado-Rosselli 2005). Esto se ve reflejado en una mayor capacidad de supervivencia de semillas y plántulas en la cercanía de los árboles parentales (ca. 10-15 m). Adicionalmente, Dacryodes parece presentar otras características como una extensa estación de fructificación y una permanente oferta de unos pocos frutos maduros (Parrado-Rosselli 2005) las cuales parecen minimizar la competencia por dispersores de semillas y la depredación de las mismas (Smythe 1970, Foster 1982, Wright et al. 2005).
Por otro lado, aunque en el presente estudio la depredación por vertebrados tiende a estar subestimada debido al tipo de muestreo (ver métodos), estos resultados coinciden con otros estudios en los que la depredación por vertebrados fue menor en comparación con la depredación por invertebrados y patógenos (Hammond \& Brown 1998, Hammond et al. 1999). Además, observaciones acerca de la frugivoría en los mismos individuos, realizadas antes del presente estudio indican que los vertebrados manipularon (consumo y depredación) alrededor del $20 \%$ de las semillas encontradas en un radio de $50 \mathrm{~m}$ del parental (Parrado-Rosse1li 2005, A. Parrado-Rosselli datos no publicados). Por lo tanto, en caso de que el $100 \%$ de las semillas manipuladas por vertebrados hubiesen sido depredadas, la depredación por estos seguiría siendo menor a la depredación por invertebrados y patógenos. En Brosimum la depredación por vertebrados no fue dependiente de la distancia ni de la densidad, aspecto que sugiere que los vertebrados forrajean a lo largo de sus rangos de hogar, sin ser influenciados por un gradiente de densidad de semillas (Hammond \& Brown 1998, Hammond et al. 1999). El papel de los vertebrados terrestres parece estar entonces ligado a la reacomodación y organización de la sombra de semillas que será la que dará lugar a la subsiguiente sombra de plántulas. El efecto de la depredación de semillas por vertebrados se verá probablemente mucho más pronunciado en especies con semillas más grandes y pesadas, las cuales tienden a ser preferidas por estos animales (Jansen et al. 2004). Comparaciones con un mayor rango de tamaños de frutos/semillas y muestreos de depredación por vertebrados durante toda la estación de fructificación de la(s) especie(s) podrán demostrar, con mayor contundencia, si existe o no una relación directa entre la densidad y la distancia y la intensidad de la depredación.

Aunque la depredación total de semillas fue mayor en Dacryodes que en Brosimum (45\%

Revista Colombia Forestal Vol. 10 No. 20 - Diciembre 2007 
y $26 \%$, respectivamente), los porcentajes de semillas depredadas de las dos especies en los $50 \mathrm{~m}$ de radio del parental, fueron bajos en comparación con muchas otras especies de árboles tropicales cuyos rangos de depredación oscilan entre $75 \%$ y $99 \%$ (Kiltie 1981, Smythe 1989, Fragoso 1997, Silva-Matos \& Watkinson 1998, Brewer \& Webb 2002, A. ParradoRosselli datos no publicados). Esto puede ser uno de los factores que estarían generando las altas abundancias de estas dos especies en el área de estudio (Duivenvoorden \& Lips 1993, Londoño-Vega \& Alvarez-Dávila 1997).

\section{CONSIDERACIONES SOBRE LA CORRESPONDENCIA ENTRE SEMILLAS Y PLÁNTULAS}

Se ha sugerido que la dispersión de semillas por animales puede llegar a moldear la estructura de la población de una gran cantidad de especies de árboles tropicales (Fragoso 1997, Silva-Matos \& Watkinson 1998, Bleher \& Böhning-Gaese 2001). Sin embargo, ha sido igualmente reconocida la necesidad de generar información cuantitativa que vincule las diferentes etapas de la cadena de la dispersión de semillas, pues aún se carece de evidencia suficiente para apoyar estas teorías. En este contexto, esta investigación provee evidencia adicional al respecto. Aunque es necesario correlacionar los resultados encontrados con la actividad frugívora, la mayor agregación de semillas de Dacryodes cerca al parental puede ser la consecuencia de una baja dispersión de semillas (Rozo-Mora \& Parrado-Rosselli 2004) que se mantiene en las plántulas recién establecidas y las plántulas de más de 1 año de edad. Esto, además, podría explicar el patrón agregado de distribución de árboles de DAP $>10 \mathrm{~cm}$ de Dacryodes reportados para el área de estudio. De igual forma, la distribución más extendida de semillas de Brosimum en relación a la de Dacryodes parecería ser consecuencia de una mayor y efectiva dispersión por parte de animales (Parrado-Rosselli
2005); patrón que se mantiene en estadios posteriores y que probablemente podría explicar la distribución aleatoria de adultos en el área de estudio (Parrado-Rosselli 2005). Forget (1990) en la Guyana Francesa, también encontró correspondencia entre la sombra de semillas y de plántulas para Vouacapoua americana (Caesalpiniaceae) la primera como efecto del consumo, remoción y depredación de las semillas por vertebrados. De tal forma, que estos resultados proveen de mayor evidencia acerca del papel de los animales en los patrones de ocupación de espacio de las plantas en los bosques tropicales a través de la dispersión de semillas que generan. Esto, además, tiene importantes implicaciones en el manejo de la cacería en muchos bosques tropicales, principalmente cuando afecta a los dispersores de aquellas especies de árboles que presentan distribuciones más espaciadas de los adultos y sombras de semillas y de plántulas menos leptocúrticas como en el caso de Brosimum.

A pesar de que en la presente investigación sólo se estudiaron dos especies con un reducido tamaño de muestreo para obtener conclusiones definitivas, este trabajo provee evidencia adicional para apoyar estas teorías y al debate sobre los factores que determinan los patrones de distribución espacial de especies en los bosques tropicales. Se sugiere estudiar un grupo más amplio de especies de árboles que presenten características similares tales como altas abundancias, semillas dispersadas por animales, patrones de producción de frutos regulares, sincrónicos y estacionales.

Debido a que el patrón de distribución especial de semillas y plántulas $1(<1$ año) se obtuvo para un único evento reproductivo (una sola estación de fructificación) mientras que los patrones de plántulas 2 ( $>1$ año) son producto de eventos reproductivos anteriores, las conclusiones sobre este proceso de regeneración son tentativas pues están basadas en evidencia 
limitada de un único momento en el tiempo. No obstante, aunque estudios a largo plazo son importantes, este tipo de análisis puede ser útil para predecir las consecuencias de la dispersión de semillas en la estructura de los bosques (Nathan \& Muller-Landau 2000).

\section{CONCLUSIONES}

La información generada en este estudio puede ser de gran importancia para el manejo de especies forestales al generar información sobre las distancias de óptimo reclutamiento de los individuos de las especies de árboles, y/o las distancias en dónde los efectos denso dependientes propuestos por Janzen y Connell inciden en menor grado.

Se halló una alta correspondencia entre los patrones espaciales de distribución de semillas y plántulas de Dacryodes y Brosimum, aspecto que permite sugerir que la sombra de semillas impuesta por los dispersores se mantiene en la etapa de plántulas

La distribución natural de semillas en el suelo de Dacryodes chimantensis y Brosimum utile entre los 0-50 m desde la base de los árboles parentales es leptocúrtica y concentrada hacia el parental.

El porcentaje total de semillas de depredadas fue menor en Brosimum que en Dacryodes. La depredación de semillas de Brosimum estuvo altamente agregada en la cercanía al árbol parental mientras que para Dacryodes estuvo mejor distribuida a lo largo de los $50 \mathrm{~m}$.

La depredación de semillas de las dos especies estuvo positivamente correlacionada con la densidad de semillas y negativamente correlacionada con la distancia al parental.

La sombra de plántulas menores a un año, recientemente establecidas o de estación de fructificación inmediatamente anterior fue más leptocúrtica en Dacryodes y estuvo más concentrada en la cercanía del parental que en Brosimum. La distribución de la sombra de plántulas mayores a un año presentó patrones contrastantes entre las dos especies.

El daño o depredación potencial de plántulas mayores y menores a un año fue mayor en Dacryodes que en Brosimum, estuvo positivamente correlacionada con la densidad y negativamente correlacionada con la distancia al árbol parental.

Se sugieren estudios con un mayor número de especies, comparaciones con un mayor rango de tamaños de frutos/semillas y muestreos de remoción y depredación por vertebrados durante toda la estación de fructificación.

\section{AGRADECIMIENTOS}

Muchas gracias a la comunidad indígena Nonuya de Peña Roja y al personal de Tropenbos-Internacional Colombia por su ayuda y apoyo durante el trabajo de campo, logística e instalaciones. Agradezco al personal del Herbario Amazónico colombiano (COAH) por el acceso a sus colecciones y la ayuda en la identificación de las especies. Antoine Cleef, Henry Hooghiemstra y Dan Yeloff revisaron versiones anteriores a este manuscrito. Pablo Stevenson hizo excelentes comentarios que ayudaron a mejorar la calidad del manuscrito. Esta investigación fue financiada por la Fundación Tropenbos Internacional Colombia; Programa de Becas de la UNESCO para el apoyo de áreas prioritarias (2004-2005); la Organización de Los Países Bajos para la Cooperación Internacional en la Educación Superior (NUFFIC) y Fundación Het Kronendak. 


\section{REFERENCIAS BIBLIOGRÁFICAS}

Bleher, B. \& K. Böhning-Gaese. 2001. Consequences of frugivore diversity for seed dispersal, seedling establishment and the spatial patterns of seedlings and trees. Oecologia 129: 385-394.

Brewer, S.W. \& M.A.H. Webb. 2001. Ignorant seed predators and factors affecting the seed survival of a tropical palm. Oikos 93: 32-41.

Castaño-A., N. 2003. Estimación de la oferta de frutos en el gradiente vertical de un bosque de tierra firme del Medio Río Caquetá, Amazonía colombiana. Tesis de Pregrado. Universidad Nacional de Colombia, Bogotá.

Clark, J.S., B. Beckage, P. Camill, B. Cleveland, J. Hillerislambers, J. Lichter, J. McLachlan, J. Mohan \& P. Wyckoff. 1999. Interpreting recruitment limitation in forests. American Journal of Botany 86: 1-16.

Connell, J.H. 1971. On the role of natural enemies in preventing competitive exclusion in some marine animals and in rain forest trees. Pgs. 298-312 en P.J. den Boer \& P.R. Gradwell (eds). Dynamics of Populations. Pudoc, Wageningen, Países Bajos.

De Steven, D. \& F.E. Putz. 1984. Impact of mammals on early recruitment of a tropical canopy tree, Dipteryx panamensis, in $\mathrm{Pa}$ nama. Oikos 43: 207-216.

Duivenvoorden, J.F. \& J.M. Lips. 1993. Ecología del paisaje del Medio Caquetá. Memoria explicativa de los mapas. Estudios en la Amazonía colombiana. III A-III B. Tropenbos-Colombia, Bogotá. 301 pp.
Duivenvoorden, J.F. 1995. Tree species composition and rain forest-environment relationships in the Middle Caquetá area, Colombia, NW Amazonia. Vegetatio 120: 91-113.

Duque, A., J. Cavelier \& A. Posada. 2003. Strategies of tree occupation at the local scale in terra firme forests in the Colombian Amazon. Biotropica 35: 20-27.

Forget, P.M. 1990. Seed dispersal of $\mathrm{VO}$ ucapoua americana (Caesalpinaceae) by caviomorph rodents in French Guiana. Journal of Tropical Ecology 6: 459-468.

Forget, P.M. 1992. Seed removal and seed fate in Gustavia superba (Lecythidaceae). Biotropica 24: 408-414

Foster, R.B. 1982. The seasonal rhythm of fruit fall on Barro Colorado Island. Pgs. 151-172 en E.G. Leigh, A.S. Rand \& D.M. Windsor (eds.). The ecology of a tropical forest: seasonal rhythms and long term changes. Smithsonian Institution Press, Washington D.C. Estados Unidos.

Fragoso, J.M. 1997. Tapir-generated seed shadows: scale-dependent patchiness in the Amazon rain forest. Journal of Ecology 85: 519 - 529 .

Gentry, A.H. 1988. Changes in plant community diversity and floristic composition on environmental and geographical gradients. Annals of the Missouri Botanical Garden 75: 1-34.

Hamill, D. \& S.J. Wright. 1986. Testing the dispersion of juveniles relative to adults: a new analytic method. Ecology 67: 952-957.

Hammond, D.S. \& V.K. Brown. 1998. Disturbance, phenology and life-history 
characteristics: factors influencing distance/density-dependent attack on tropical seeds and seedlings. Pgs 51-78 en D.M. Newberry, H.H.T. Prins \& N.D. Brown (eds.). Dynamics of Tropical Communities. Blackwell Science, Oxford, Reino Unido.

Hammond, D.S., V.K. Brown \& R. Zagt. 1999. Spatial and temporal patterns of seed attack and germination in a large-seeded neotropical tree species. Oecologia 119: 208-218.

Hladik, A. \& D. Mitja. 1996. Seedlings, saplings and tree temperaments: potential for agroforestry in the African rain forest. Pgs. 173-192 en M.D. Swaine (ed.) The Ecology of Tropical Forest Tree Seedlings. Man and the Biosphere Series: V.17. UNESCO and The Parthenon Publishing Group, París, Francia.

Howe, H. \& J. Smallwood. 1982. Ecology of seed dispersal. Annual Review of Ecology and Systematics 13: 201-228.

Howe, H.F., E.W. Schupp \& L.C. Westley. 1985. Early consequences of seed dispersal for a neotropical tree (Virola surinamensis). Ecology 66: 781-791

Hubbell, S.P. 1998. The maintenance of diversity in a neotropical tree community: conceptual issues, current evidence, and challenges ahead. Pgs. 17-44 en F. Dallmeier \& J.A. Cominsky (eds.). Forest Biodiversity Research, Monitoring and Modeling: Conceptual Background and Old World Case Studies. UNESCO and The Parthenon Publishing Group, París, Francia.

Jansen, P.A., F. Bongers \& L. Hemerik. 2004. Seed mass and mast seeding enhance dispersal by a neotropical scatter-hoarding rodent. Ecological Monographs 74: 569-589.
Janzen, D. 1970. Herbivores and the number of tree species in tropical forests. The American Naturalist 104: 501-528.

Janzen, D.H. (1991). Historia natural de Costa Rica. The University of Chicago Press, Illinois.

Janzen, D.H., G.A. Miller, J. Hackforth-Jones, C.M. Pond, K. Hooper \& D.P. Janos. 1976. Two Costa Rican Bat-generated seed shadows of Andira inermis (Leguminosae). Ecology 57: 1068-1075.

Jordano, P. \& J. Godoy. 2002. Frugivore-generated seed shadows: a landscape view of demographic and genetic effects, pp. 305-321 en D.J. Levey, W.R. Silva \& M.Galetti, (eds.). Seed Dispersal and Frugivory: Ecology, Evolution and Conservation. $\mathrm{CAB}$ International, Wallingford, Reino Unido.

Kiltie, R.A. 1981. Distribution of palm fruits on a rain forest floor: Why white-lipped peccaries forage near objects. Biotropica 13: $141-145$

Londoño-Vega, A.C. \& E. Alvarez-Dávila. 1997. Composición florística de dos bosques (tierra firme y várzea) en la región de Araracuara, Amazonia colombiana. Caldasia 19: 431-463.

Nathan, R. \& H. Muller-Landau. 2000. Spatial patterns of seed dispersal, their determinants and consequences for recruitment. Trends and Ecology and Evolution 15: 278-285.

Parrado-Rosselli, A. 2005. Fruit availability and seed dispersal in terra firme rain forests of Colombian Amazonia. Tropenbos $\mathrm{PhD}$ Series 2, Tropenbos-International, Wageningen, Países Bajos. Versión en línea 
URL: http://www.tropenbos.org/files/Colparrado.htm

Parrado-Rosselli, A. en prensa. La dispersión de semillas: una herramienta para comprender la composición y estructura de los Bosques Amazónicos, pp: 109-116. En: CORPOAMAZONIA - IAVH (Eds.) Plan de Acción Regional en Biodiversidad de la Región Sur Amazónica Colombiana. Instituto Alexander von Humboldt - Instituto SINCHI - Corpoamazonia.

Parrado-Rosselli, A., J. Cavelier \& A. van Dulmen. 2002. Effect of fruit size on primary seed dispersal of five canopy tree species of the Colombian Amazon". Selbyana 23: 245-257.

Parrado-Rosselli, A., J.L. Machado, \& T. Prieto-López. 2006. Comparison between two methods for measuring fruit production in a tropical forest. Biotropica 38: 267-271.

Rozo-Mora, M.C. \& A. Parrado-Rosselli. 2004. Dispersión primaria diurna de semillas de Dacryodes chimantensis y Protium paniculatum (Burseraceae) en un bosque de tierra firme de la amazonia colombiana. Caldasia 26: 111-124.

Sánchez-Cordero, V. \& R. Martínez-Gallardo. 1998. Postdispersal fruit and seed removal by forest-dwelling rodents in a lowland rainforest in Mexico. Journal of Tropical Ecology 14: 139-151.

Schupp, E.W. 1990. Annual variation in seedfall, postdispersal predation, and recruitment of a neotropical tree. Ecology 71:504-515

Schupp, E.W. 1992. The Janzen-Connell model for tropical tree diversity: population implications and the importance of spatial scale. American Naturalist 140:526-530.

Schupp, E.W., T. Milleron \& S.E. Russo. 2002. Dissemination limitation and the origin and maintenance of species rich tropical forests. Pgs. 19-33 en D.J. Levey, W.R. Silva \& M.Galetti, (eds.). Seed Dispersal and Frugivory: Ecology, Evolution and Conservation. CAB International, Wallingford, Reino Unido.

Silva Matos, D.M. \& A.R. Watkinson. 1998. The fecundity, seed and seedling ecology of the edible palm Euterpe edulis in southeastern Brazil. Biotropica 30: 595 - 603.

Smythe, N. 1970. Relationships between fruiting seasons and seed dispersal methods in a neotropical rain forest. The American Naturalist 104: 25-35.

Smythe, N. 1989. Seed survival in the palm Astrocaryum standleyanum: evidence for dependence upon its seed dispersers. Biotropica 21: 50-56.

Snow, D.W. 1962. The natural history of the oilbird, Steatornis caripensis, in Trinidad, part 2: population, breeding, ecology and food. Zoologica 47: 199-221.

Statsoft. 1999. Statistica for Windows. StatSoft, Inc., Tulsa, USA.

Stevenson, P.R., M.J. Quiñonez \& M.C. Castellanos. 2000. Guía de frutos de los bosques del Río Duda, La Macarena, Colombia. IUCN, Bogotá.

Tuomisto, H., K. Ruokolainen, R. Kalliola, A. Linna, W. Danjoy \& Z. Rodriguez. 1995 Dissecting Amazonian Biodiversity. Science 269: 63-66. 
Wright, S.J. 2002. Plant diversity in tropical forests: a review of mechanisms of species coexistence. Oecologia 130: 1-14.

Wright, S.J., H.C. Muller-Landau, O. Calderón \& A. Hernández. 2005. Annual and spatial variation in seed fall and seedling recruitment in a neotropical forest. Ecology $86: 848-860$.

Zar, J.H. 1984. Biostatical Analysis. Second edition. Prentice-Hall, New Jersey. 